Currículo sem Fronteiras, v. 20, n. 1, p. 209-232, jan./abr. 2020

\title{
STEM EDUCATION \\ - um panorama e sua relação com a educação brasileira
}

\author{
Gustavo Oliveira Pugliese \\ Universidade de São Paulo - USP
}

\begin{abstract}
Resumo
STEM education (Science, Technology, Engineering and Mathematics) é um movimento ligado à educação que traz ênfase nas quatro áreas do acrônimo para o ensino de ciências. Esse movimento tem ocupado espaço significativo não só nas escolas, mas também nos discursos e na agenda política de diversos países, sendo, portanto, global. Entretanto, ainda não há consenso em relação aos múltiplos sentidos que o STEM education toma, pois diferentes grupos fazem diferentes usos da ideia. Sua dimensão em alguns países levanta dúvidas em relação às formas pelas quais pode ser visto dentro da pesquisa em ensino de ciências, bem como sua presença no Brasil deve ser melhor elucidada. Portanto, esse artigo tem três propósitos: apresentar um panorama do STEM education no mundo e no Brasil a partir da revisão da literatura; discutir como o movimento pode ser compreendido na pesquisa de ensino de ciências; e debater sobre as consequências dessa tendência no nosso sistema educacional.
\end{abstract}

Palavras-chave: STEM education. Políticas educacionais. Modelos de ensino. CTS.

\begin{abstract}
STEM education (Science, Technology, Engineering and Mathematics) is an education movement that brings emphasis in these four areas of the acronym for science education. This movement has occupied significant space not only in schools, but also in speeches and in the political agenda of several countries, being therefore global. However, there is no consensus yet regarding the multiple meanings STEM education takes, as different groups make different uses of the idea. Its size in some countries raises doubts about the ways in which it can be seen within research in science education, and its presence in Brazil should be better elucidated. Therefore, this article has three purposes: to present a panorama of STEM education in the world and in Brazil from the literature review; discuss how movement can be understood in science teaching research; and discuss what kind of STEM education reform will influence our educational system.
\end{abstract}

Keywords: STEM education. Educational policies. Teaching models. STS. 


\section{Introdução - O movimento STEM}

No que diz respeito aos sistemas educacionais, diversos países têm se voltado para um formato de educação que enfatiza a Ciência, Tecnologia, Engenharia e Matemática, o chamado STEM education (Science, Technology, Engineering and Mathematics). Esse novo formato ganhou proporções significativas principalmente nos Estados Unidos. O termo foi introduzido pela National Science Foundation (NSF) dos EUA nos anos 1990 como SMET (SANDERS, 2009; ENGLISH, 2016). Apesar disso, apenas na última década começou a ganhar visibilidade, especialmente a partir de 2001, quando uma das diretoras do NSF sugeriu o termo STEM ao invés de SMET (SANDERS, 2009; BREINER et al., 2012), e hoje se configura como uma tendência global.

STEM education pode significar o óbvio à primeira vista: o ensino de ciências e matemática incrementado com novos conteúdos de novas áreas que ganharam espaço na sociedade nas últimas décadas, principalmente a computação. Tudo isso acrescido de novas metodologias de ensino. Entretanto, como veremos adiante, o termo hoje possui uma conotação muito mais complexa e emaranhada de significados. A definição de STEM education é ainda muito instável e não há uma universal. Apesar de diferentes definições terem sido propostas, ainda é um termo confuso e ambíguo (BREINER et al., 2012; BELL, 2016; WONG et al., 2016).

Para amenizar a profusão de sentidos que a busca por uma definição pode causar, é possível, contudo, observar características que permitem uma primeira compreensão. Em termos gerais, a partir da literatura, mídia não especializada e informações vindas de programas educacionais STEM, algumas constantes podem ser atribuídas ao movimento como um todo.

\section{Em busca de significado}

STEM education se apresenta como uma proposta inovadora no ensino de ciências. Há uma ideia de rompimento com o ensino tradicional passivo de ciências, no qual o aluno pouco interage com o objeto de estudo e não vê conexões com o mundo empírico. Frequentemente os programas educacionais $\mathrm{STEM}^{1}$, tanto governamentais, quanto não governamentais, advogam que STEM education é uma forma libertadora do tradicionalismo e da aprendizagem não participativa, substituindo-os pela aprendizagem baseada em projetos (BREINER et al., 2012) e conectados às futuras escolhas profissionais (REISS; MUIJTABA, 2017). Como veremos adiante, a origem do movimento STEM education está intimamente associada com o desinteresse de jovens pelas carreiras STEM (CANNADY et al., 2014; RITZ; FAN, 2015; REISS; MUJTABA, 2017). Por isso a preocupação em tornar a aula de ciências interessante é quase que unânime entre os programas de ensino STEM e, em alguns casos, há até mesmo direcionamento deliberado dos alunos para essas carreiras.

Também é característica do movimento a ideia de um currículo multidisciplinar, que integra as quatro áreas. Diversos autores advogam pela ideia de STEM integration como 
princípio norteador das práticas pedagógicas, embora seja possível notar que o significado de integração e a sua efetivação seja bastante controversa (SANDERS, 2009; HONEY et al. 2014; RITZ; FAN, 2015; KELLEY; KNOWLES, 2016; ENGLISH, 2016). Tais autores argumentam que STEM tem a ideia de integração intrínseca em si, de modo que essas disciplinas não poderiam ser isoladas e ensinadas separadamente. Entretanto, English (2016) nota que, mesmo que STEM carregue consigo uma ideia de multi/transdisciplinaridade, a integração entre as áreas pode ficar restrita ao plano superficial ou fictício, como veremos adiante.

Além disso, o movimento STEM education é contemporâneo - no sentido de que possui a atenção voltada para as demandas do século XXI e traz para dentro da sala de aula de ciências áreas como computação (Tecnologia) e design (Engenharia). Nesse sentido, busca atender à demanda por conhecimentos e habilidades que são considerados cruciais para o século XXI (BECKER; PARK, 2011; OBAMA, 2014; HOEG; BENCZE, 2017), além de comumente estar conectado com o contexto atual de desafios globais (BYBEE, 2013). Para Ritz e Fan (2015), a reforma educacional STEM é essencialmente diferente das outras porque está atrelada a resolver os problemas globais e econômicos. Contudo, é possível perceber nessa reforma um formato de ciência positivista, neutra e determinista impresso nos discursos, bem como um otimismo tecnológico em relação aos problemas ambientais (FEINSTEIN; KIRCHGASLER, 2015; ZEIDLER, 2016), principalmente quando se trata de justificar a ênfase em STEM como crucial para a sustentabilidade do planeta. Feinstein e Kirchgasler (2015) pontuam sobre essa abordagem:

Ao invés de apoiar uma geração de estudantes para se envolver com a ciência de maneiras realistas e produtivas, como eles abordam desafios de sustentabilidade, essa abordagem pode levar os alunos a mal interpretar e subestimar sistematicamente os desafios que enfrentam suas comunidades locais, regionais e globais. (FEINSTEIN; KIRCHGASLER, 2015, p. 123) [Tradução livre]

Ainda dentro da discussão sobre o que constitui a essência do movimento STEM education, surge uma questão em torno da conexão de STEM com as artes dando origem ao termo STEAM (Science, Technology, Engineering, Arts and Mathematics). Embora esse debate não seja território pacífico, há autores que argumentam pela necessidade de se utilizar STEAM ao invés de STEM e diversas propostas já foram criadas nesse sentido (CUNNINGHAM, 2014; JOLLY, 2014; RADZWILL; BENTON; MOELLERS, 2015; THURLEY, 2016). Cunningham (2014) coloca que, ao contrário da ciência e tecnologia, o que as artes têm a acrescentar ao sistema educacional vai além de retornos monetários, e que STEM por si só se torna esvaziado de sentido. Para Radziwill et al. (2015), a arte e o design teriam uma função de engajar os estudantes em ciência e tecnologia e tornar o ambiente de aprendizagem mais produtivo e substancial. Para Blackley e Howell (2015, p. 17), “A educação STEM, tipicamente concebida e praticada, carece de 'STEAM'. Um foco em STEM sem 'Artes' exclui necessariamente áreas importantes que informam e contextualizam a ciência, fundamentando-as em contextos socioculturais.” (BLACKLEY; HOWELL, 2015, 
p. 17) [Tradução livre]. Na visão desses autores, artes incluem, por exemplo, sociologia, psicologia, história, artes visuais, filosofia e educação.

Porém, questiona-se de que forma o campo Arte entra no movimento, afinal é comum uma visão de arte estritamente utilitarista: "serve para ilustrar”, não propriamente como um campo do conhecimento. Ou até mesmo uma visão instrumentalista e de entretenimento: "serve para tornar interessante". Nesse caso, a função sensibilizadora, educadora, criativa, crítica ou estética não são preconizadas, tampouco os conceitos, debates, valor social e técnicas, o que coloca em questionamento qual a verdadeira posição das artes no acrônimo.

\section{Três fatores que explicam a corrida por STEM education nos EUA e as políticas em torno do movimento}

É imprescindível compreender que STEM education é um movimento que nasce nos EUA e então se dissemina para outros países, mas carregando marcas características do sistema educacional estadunidense. A partir da revisão da literatura, é possível enumerar ao menos três fatores que explicam esse processo.

O primeiro deles, mais intuitivo, é o espaço que a inovação adquiriu nas sociedades, associado às transformações tecno-científicas as quais nos influenciam seja na sala de aula, seja vida quotidiana. Tornou-se impossível ignorar que o mundo ao redor das crianças havia mudado profundamente e que seria necessário acompanhar essas transformações e reformulando o currículo. Entre os argumentos dos entusiastas do STEM education, é comum a constatação de um currículo desatualizado nas escolas, o qual não se conecta com as vivências e experiências externas a ele, ou com a cultura tecnológica da sociedade contemporânea.

Lopes e Macedo (2011) trazem que a perspectiva instrumental do conhecimento atua como propulsor dessa necessidade de mudança curricular. Para as autoras, um currículo baseado na perspectiva instrumental "(...) tem a finalidade de formar cidadãos capazes de gerar um benefício mais amplo para a sociedade.” (LOPES; MACEDO, 2011, p.74). Do ponto de vista de uma sociedade industrializada, esse benefício se traduz na mão-de-obra que o mercado demanda. Portanto, STEM education aparece como uma resposta a um currículo desconectado das exigências da indústria contemporânea e do mercado de trabalho ao qual os alunos estão submetidos atualmente. E é por isso que as propostas STEM estão em geral alinhadas com a chamadas competências (ou habilidades) do século XXI, mais recentemente difundidas como objetivos curriculares a serem alcançados (OBAMA, 2015). Da mesma forma, estão alinhadas com as recomendações do Next Generation Science Standards (NGSS), um documento publicado nos EUA em 2013 com função muito equivalente à dos PCN (Parâmetros Curriculares Nacionais) do Brasil, ou da mais recente Base Nacional Comum Curricular.

O segundo fator é a publicação de uma série de relatórios indicando que os EUA passavam por uma escassez de profissionais capacitados nas áreas STEM e que perderiam competitividade econômica por isso (MAY; CHUBIN, 2003; KUENZI et al, 2006; 
NATIONAL ACADEMIES PRESS, 2006; BECKER; PARK, 2011; KUENZI et al.2011; ENGLER, 2012; ANFT, 2013; KELLEY; KNOWLES, 2016). Esses relatórios causaram grande perturbação nas agências reguladoras da educação nos EUA e foram incendiários na mídia, gerando um senso generalizado de crise (presente até hoje) nas áreas STEM (CHARETTE, 2013; SANDERS, 2009; RITZ; FAN, 2015; WONG et al, 2016; XUE; LARSON, 2015).

A noção de crise no mercado de trabalho é uma das mais relevantes para compreender as reações que emergem na forma de STEM education como solução. Está em sua gênese a ideia de que essas áreas são vitais para a era tecnológica na qual as sociedades estão inseridas atualmente, ideia essa introduzida por um mercado cada vez mais presente nas esferas políticas e educacionais. Mais especificamente, diversos autores (BREINER et al., 2012; RITZ; FAN, 2015; XUE; LARSON, 2015; WONG et al. , 2016) creditam boa parte dessa noção de crise nos EUA à publicação especificamente de um relatório por parte do National Research Council, intitulado Rising Above The Gathering Storm (NATIONAL ACADEMIES PRESS, 2006). O relatório sugeria que “(...) A vantagem competitiva dos EUA em ciência e tecnologia estava sendo erodida e argumenta que uma das principais estratégias para atacar essa questão seria através da vasta melhoria de matemática e ensino de ciências.” (WONG et al. 2016, p. 2348) [Tradução livre]. Banning e Folkestad (2012) colocam que para os autores do relatório,

(...) um enfraquecimento da ciência e da tecnologia nos Estados Unidos inevitavelmente degradaria suas condições sociais e econômicas e, em particular, prejudicaria a capacidade de seus cidadãos competir por empregos de alta qualidade'. (AUGUSTINE 2008, apud BANNING; FOLKESTAD, 2012, p. 730) [Tradução livre].

Sanders (2009) credita parte do que ele chama de STEMmania a um best-seller intitulado The World is Flat (FRIEDMAN, 2005). Para o autor, o livro

\footnotetext{
“(...) convenceu os americanos de que os EUA estavam perdendo espaço para a China e a Índia na economia global. Friedman mostrou os papéis que STEM e STEM education desempenham na competição global por riqueza e poder. A América corporativa ouviu a mensagem e a engrenagem política começou a girar.” (SANDERS, 2009, p. 25)
}

Como consequência, "O financiamento começou a fluir em direção a qualquer coisa que fosse STEM, e a STEMmania estava estabelecida. Agora, qualquer pessoa está de alguma forma familiarizada com a sigla STEM.” (SANDERS, 2009, p. 20)

O terceiro fator consiste na publicação de relatórios internacionais indicando baixo desempenho e interesse dos estudantes norte-americanos em várias áreas, incluindo ciências (OECD, 2003; AINLEY; AINLEY, 2011; KUENZI et al, 2006; NATIONAL ACADEMIES PRESS, 2006; SAXTON et al.2014; CARO; LENKEIT, 2015; ZAKARIA, 2015; ZEIDLER, 2016). Saxton et al. (2014) e Kuenzi et al. (2006) apontam tanto esse baixo desempenho dos 
estudantes, quanto a escassez de professores capacitados em STEM education como as causas de uma crise educacional. Gough argumenta que o ensino de ciências como um todo passaria por um estado de crise:

Aspectos dessa crise incluem desde uma decrescente proporção de alunos estudando ciências, particularmente física, tanto na escola quanto nas universidades, até o ponto no qual há escassez de profissionais de ciências capacitados e professores de ciências bem preparados, além do contínuo, senão crescente, desencanto e desengajamento estudantil com a ciência escolar no ensino básico. (Gough, 2014, p. 446) [Tradução livre]

Todavia, autores revelam que toda a comoção em torno da ideia de crise econômica e educacional seja, na verdade, um construto econômico e político, além de puramente especulativa. (ANFT, 2013; CHARETTE, 2013; TEILTEBAUM, 2014; XUE; LARSON, 2015; BLACKLEY; HOWELL, 2015). Tais autores se valem de dados bastante convincentes para mostrar que a escassez de profissionais STEM deveria ser relativizada, além de sugerirem que propagar a ideia de crise nessas áreas é benéfico para determinados setores da economia, mesmo que a crise em si não exista. Tal pensamento se alinha com o que é desenvolvido por Macedo (2013), a qual traz que a ideia de crise age como legitimadora e motivadora de mudanças curriculares. Para a autora, o uso da noção de crise ocorre modo sistemático para descrição da sociedade contemporânea, não só no campo do currículo, impulsionando reformas dessa natureza.

\section{Os efeitos do movimento STEM nos Estados Unidos}

A noção de perda de competitividade como catalisador do movimento é chave para compreender a motivação em favor de STEM que vem principalmente do setor econômico ${ }^{2}$. E ajuda a entender porque a proposta STEM de mudança no currículo está ligada à busca pelo desempenho ótimo do currículo escolar para que ele forme cidadãos competitivos para o mercado de trabalho globalizado e multidisciplinar, algo já discutido por Stephen Ball:

Cada vez mais, as políticas sociais e educacionais estão sendo articuladas e legitimadas explícita, direta e, muitas vezes, exclusivamente em função do seu papel em aumentar a competitividade econômica por meio do desenvolvimento das habilidades, capacidades e disposições exigidas pelas novas formas econômicas da alta modernidade. (BALL, 2004, p. 1109)

O fato é que STEM education emergiu, mesmo que de maneira forçosa (ver Bybee (2013)), como uma resposta para tais questões. Toda essa perturbação provocou uma reação em órgãos públicos norte-americanos, entidades ligadas aos programas educacionais, legisladores e na Casa Branca, e também em grandes corporações, os quais atuaram através de programas de incentivo à STEM nas escolas, seja via financiamento público-privado, seja 
por patrocínio de programas educacionais (OBAMA, 2014; THE WHITE HOUSE, 2016). Inúmeras lideranças estabeleceram e ainda têm estabelecido verdadeiras forças-tarefas para garantir que cada Estado seja uma liderança em STEM education (ver: STEM Task Force Report, 2014; Washington STEM, 2017). Hoeg e Bencze (2017, p. 16) notam que há até uma pressão política institucionalizada para implementação dos programas STEM: “Os Estados não ganham recursos federais a menos que eles enfatizem STEM nas políticas educacionais e conectado a instrumentos de avaliação de desempenho (por ex. pagamento por mérito e sistemas de ranqueamento escolar). " [Tradução livre]

Não é incomum em artigos da mídia estadunidense e alguns autores uma visão catastrofista caso os EUA não adotem uma postura pró-STEM (BYBEE, 2013). Foi criado um verdadeiro duto (pipeline, como os próprios defensores de STEM se referem) para direcionar os alunos para as carreiras STEM, principalmente sob o argumento de que a escassez de profissionais dessas áreas ameaça seriamente a integridade e segurança nacional (NATIONAL ACADEMIES PRESS, 2006; BYBEE, 2013; CANNADY et al. , 2014; BELL, 2016). Cannady et al., (2014) e Banning e Folkestad criticam duramente tanto o uso da metáfora de pipeline, quanto a adoção de tais medidas, uma vez que elas visam atender às necessidades econômicas e reforçam a ideia de que os alunos que não seguem tais carreiras são inúteis para a prosperidade econômica ou, nos termos da metáfora, são considerados como desperdício (leaky pipeline), além de não considerar as razões pelas quais minorias não representadas em STEM não seguem essas carreiras, aumentando a desigualdade de oportunidades.

Nos EUA, STEM se tornou a palavra-chave para as escolas e universidades que querem se alinhar com as políticas do Estado (BREINER et al., 2012), como é possível perceber a partir da fala do ex-presidente Barack Obama: "Nós precisamos fazer disso uma prioridade, para treinar um exército de novos professores nessas áreas [STEM], e ter certeza de que todos nós como um país estamos dando o devido reconhecimento que essas áreas merecem." (OBAMA, 2013b apud BELL, 2016, p. 63) [Tradução livre]. Na mídia em geral, nos relatórios, documentos oficiais, nas missões institucionais de programas e nos artigos acadêmicos (tanto apoiadores quanto críticos do movimento STEM), é quase impossível não se deparar com o mantra “A mão-de-obra STEM é vital para nossa vitalidade econômica. Os empregos STEM são os empregos do futuro. Eles são essenciais para nossa inovação tecnológica e competitividade global” (LANGDON et al, 2011, p. 6) [Tradução livre]. Hoje, STEM education é uma top priority em termos de financiamento público estadunidense, os investimentos são massivos e ultrapassam a casa dos bilhões de dólares facilmente nos EUA. (BREINER et al., 2012),

\section{Movimento para além dos Estados Unidos: cenário internacional}

Embora tenha focado nesse artigo na origem do movimento nos EUA, trata-se claramente de uma tendência internacional. A partir de revisões de diversos autores, nota-se que Reino Unido e Austrália são os países nos quais, além dos EUA, o movimento assume 
maiores proporções e se desenvolve há mais tempo (BLACKLEY; HOWELL, 2015; MARGINSON et al, 2013; RITZ; FAN, 2015; WONG et al, 2016). No Reino Unido, por exemplo, o relatório Get SET for Success (2006) teve um impacto muito similar ao do relatório Rising above the Gathering Storm e, juntamente com outros, desencadearam uma série de ações como a criação de um programa nacional em STEM (STEM Cohesion Program) (WONG et al., 2016). Os autores chamam a atenção para a criação de redes políticas do Estado para “atacar o problema” (p. 2349). Segundo Bell (2016), a estratégia utilizada lá para criar uma força-trabalho bem motivada e altamente qualificada de professores STEM é por meio de incentivos financeiros. Na Austrália, as motivações (ideia de crise) e as respostas (altos investimentos e a promoção de uma imagem positiva da ciência) ocorrem de maneira muito parecida com o que ocorre nos EUA e Reino Unido (MARGINSON et al. e ROBERTS, 2013; BLACKLEY; HOWELL, 2015).

Além dos três países citados acima, no Canadá, França, China, África do Sul, Japão, para citar apenas alguns, STEM education já faz parte dos debates educacionais ocupando posição destacada (MARGINSON et al., 2013; RITZ; FAN, 2015). Um discurso de STEM é prevalente em muitos outros países e autores sugerem que as lógicas para a agenda STEM são variadas e limitadas ao mesmo tempo, e relacionadas principalmente para objetivos vocacionais (formação de mão-de-obra) e econômicos (WONG et al., 2016). Blackley e Howell (2015) sugerem que há quatro grandes reinos STEM: (1) Países Anglófonos, (2) Países da Europa Ocidental, (3) Países Asiáticos e (4) Países em desenvolvimento.

A abordagem STEM dos países de língua inglesa é dominada pelos EUA e Reino Unido e caracteriza-se por falar amplamente sobre uma "crise STEM". Há uma série de países da Europa Ocidental, como a França e a Alemanha, que enfatizaram STEM há algum tempo como parte do enquadramento da política nacional em educação e indústria; $\mathrm{O}$ foco nesses países tem sido a aparente "escassez de STEM" em vez de "crise". Normalmente, essas políticas ou estratégias envolvem: 'promoção de uma imagem positiva da ciência; crescente conhecimento público da ciência; melhorar a matemática e a ciência escolar (ensino e aprendizagem); e crescente interesse e participação em matemática e ciência escolar, disciplinas STEM terciárias e força de trabalho STEM' (Marginson et al., 2013, p. 104) (...). Além disso, os países com sucesso da STEM na Ásia possuem estruturas de carreira meritocráticas que reconhecem a excelência no ensino dessas matérias (Marginson et al., 2013) (...). Finalmente, no quarto grupo, os países em desenvolvimento com uma base industrial emergente e/ou baixos níveis de participação e oferta de professores qualificados, como o Brasil e a África do Sul, STEM é abordado em termos de melhoria da participação no ensino básico e desenvolver uma força de trabalho qualificada. BLACKLEY; HOWELL (2015, p. 110) [Tradução livre]

É difícil delimitar precisamente STEM education em cada país. Faltam estudos e evidências para estabelecer um estado da arte internacional, apesar de alguns autores terem feito importantes avanços nessa direção (MARGINSON et al, 2013; RITZ; FAN, 2015; 
WONG et al, 2016). Entretanto faltam contribuições no sentido de entender os impactos desse movimento no ensino \& aprendizagem de ciências e na alfabetização científica, por exemplo, uma vez que grande parte dos estudos se concentram nas interpretações feitas do STEM education como tendência.

\section{Cenário Brasileiro}

Se compararmos com a atenção dada ao STEM education em outros países, no Brasil (e na América Latina) o movimento ainda é tímido. Por exemplo, as revistas científicas brasileiras da área de educação não trazem nenhuma publicação relativa à STEM education. O banco de teses e dissertações do Centro de Documentação em Ensino de Ciências CEDOC, da Faculdade de Educação da Unicamp, não traz nenhum trabalho publicado ou em andamento sobre o tema. Na mídia, o que se observa são pequenas reportagens, feitas em caráter introdutório e reproduzindo a ideia de que se trata de uma proposta inovadora e em alta no exterior, mas sem grandes aprofundamentos metodológicos ou debates sobre os princípios pedagógicos ${ }^{3}$. Entretanto, é possível perceber certa presença direta do movimento no Brasil através de três frentes: programas educacionais STEM por iniciativa de organizações não-governamentais com foco na escola pública; empresas educacionais que oferecem atividades STEM como produto; e escolas privadas que implementaram atividades STEM/STEAM.

É preciso notar que em qualquer uma das frentes, os discursos pró-STEM vêm quase que invariavelmente associando-o como um "modelo de sucesso" nos EUA. No caso das organizações não governamentais, elas têm trabalhado politicamente para que programas STEM cheguem até a escola pública. É perceptível o respaldo, financiamento e operacionalização feitos por meio de doações de empresas estadunidenses ou multinacionais para que essas organizações se tornem referência STEM. No caso das empresas educacionais e das escolas privadas, ocorre o mesmo não no sentido do financiamento para programas STEM, mas sim de que o modelo estadunidense de STEM education é apresentado como argumento para sustentar e orientar os programas STEM nas escolas privadas.

O formato de desenvolvimento ainda incipiente do STEM education no Brasil não significa que a tendência internacional apenas tangenciou o país. Muito pelo contrário, há muito significado nessa baixa expressividade de programas STEM education no Brasil, quando comparado com outros países. Algumas dessas frentes que têm difundido o STEM education no Brasil parecem utilizá-lo mais como uma vantagem de mercado, pela adoção de um discurso privilegiado e importado de “países de primeiro mundo”. É possível perceber sobretudo justificativas pautadas na necessidade de desenvolver competências para o mercado de trabalho do séc. XXI e embasadas em um currículo organizado por competências, um discurso que entende a escola como aquela que prepara o aluno para a vida profissional ${ }^{4}$.

Para Ritz e Fan (2015) o movimento talvez não se materialize em muitos países, porque pode não ser apropriado para determinadas culturas, no caso, econômicas. É nesse sentido que notamos também uma presença indireta do movimento no Brasil. Muitos dos princípios 
que regem a reforma educacional STEM nos EUA são também compartilhados pelas políticas educacionais do Brasil. Por exemplo, a mais recente reforma curricular do Ensino Médio aprovada na forma de Projeto de Lei de Conversão (PLV 34/2016) e a Base Nacional Comum Curricular (BNCC) prevista para entrar em vigor a partir de 2019, foram embasadas e justificadas por sistemas educacionais de outros países, incluindo os EUA (BRASIL, 2016; RIGHETTI, 2017; TAKAHASHI, 2017), embora não façam uso do termo STEM education.

Ademais, vê-se que a percepção pública dos brasileiros em relação à Ciência e Tecnologia (C\&T) é extremamente otimista. A maioria dos brasileiros (73\%) declara acreditar que C\&T traz "só benefícios” ou “mais benefícios do que malefícios” para a humanidade (MCTIC, 2017). Quando perguntados se os investimentos em C\&T deveriam aumentar, os brasileiros se mostram ainda mais positivos em relação à C\&T, como mostra a figura 1:

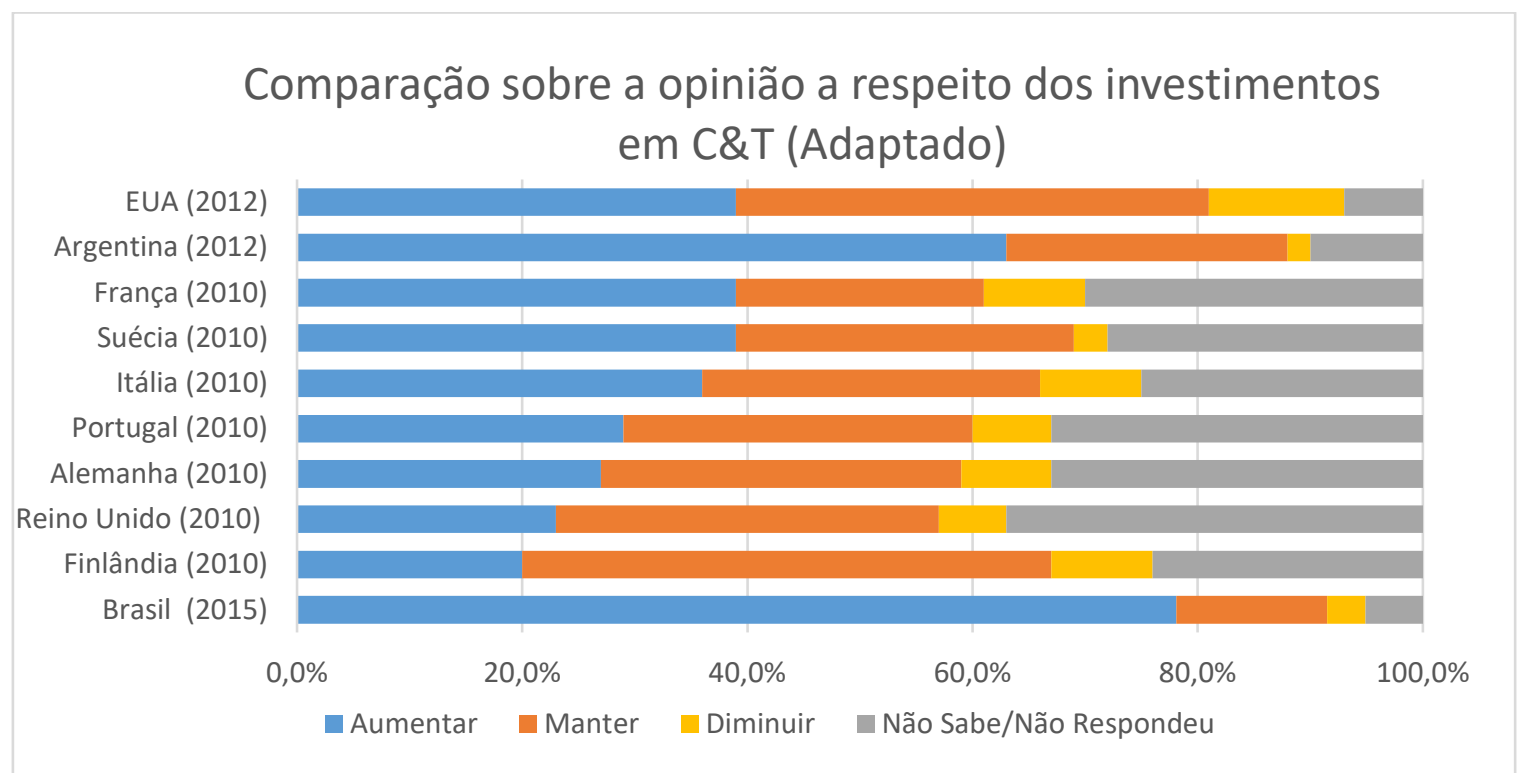

Figura 1: Percepção sobre os investimentos em C\&T. Adaptado de: MCTIC, 2017

A população de 15 anos participante do PISA (Programme for International Student Assessment) 2015 revelou alto interesse em seguir carreiras na área de ciências: 40\% dos alunos brasileiros desejam se tornar cientistas, enquanto a média da OECD (Organization for Co-operation and Development) é 25\% (OECD, 2016). Apesar da visão otimista em relação à C\&T, os resultados da última avaliação do PISA em 2015, ou qualquer outro ano, mostram que o desempenho escolar das crianças brasileiras em ciências, 401 pontos, é muito abaixo da média dos países da OCDE, de 493 pontos. Em matemática, a diferença é ainda mais acentuada: 377 pontos para os estudantes brasileiros, e 490 pontos para a média da OCDE (OECD, 2016).

Essas comparações mostram que a C\&T possuem um enorme prestígio na sociedade brasileira, ao passo que o ensino de ciências e matemática é extremamente defasado em 
relação aos outros países da OCDE. Como já foi explorado anteriormente, é com base justamente nos resultados do PISA e em outros indicadores que países como EUA e Austrália desenvolveram suas corridas para o STEM education.

Dado o panorama no qual o STEM se encontra e os efeitos que sua reforma causa no sistema educacional, é válido buscar maneiras de se compreender profundamente seu real significado e impacto no Brasil. As interpretações de tal tendência estão longe de serem esgotadas, principalmente do ponto de vista da pesquisa educacional em ensino de ciências. Portanto, a seguir são desenvolvidas duas questões em torno do movimento.

\section{Dentro da pesquisa em Ensino de Ciências, qual a caracterização mais precisa que se pode fazer de STEM education?}

A primeira questão que emerge a partir desse panorama, é sobre como podemos caracterizar STEM education do ponto de vista das teorias educacionais. Atualmente não há consenso em relação ao que representa STEM education na esfera do Ensino de Ciências (BREINER et al., 2012; BELL, 2016; RADLOFF; GUZEY, 2016; WONG et al., 2016). Para Bell (2016, p. 65), "STEM é entendido como uma construção humana e não como um corpo de conhecimento 'fixo' e, portanto, é subjetivo e aberto a uma constante interpretação, construção e reconstrução pelo indivíduo” [Tradução livre]. Breiner et al. notam que a interpretação do movimento é difusa e alterna de acordo com a perspectiva em questão:

Em termos gerais, a maioria dos interessados em promover STEM atestariam que compreendem o significado, ainda que os pormenores desse construto sempre causem confusão. Esses interessados incluem representantes do governo que alocam bilhões de dólares nessa empreitada, professores de ensino básico que esperam ensinar STEM para seus alunos, pais que se debatem para compreender a necessidade de novos currículos e pedagogia, negócios que tendem a investir nos seus futuros empregados e, é claro, os estudantes, que são finalmente os produtos desses esforços. (BREINER et al., 2012, p. 3) [Tradução livre]

Na mesma direção, Blackley e Howell (2015) trazem, por exemplo, que STEM se faz SteM nas escolas e sTEm fora delas. Todavia, identifico ao menos quatro possibilidades, não mutuamente excludentes, de classificar o STEM education, conforme mostra a figura 2. 


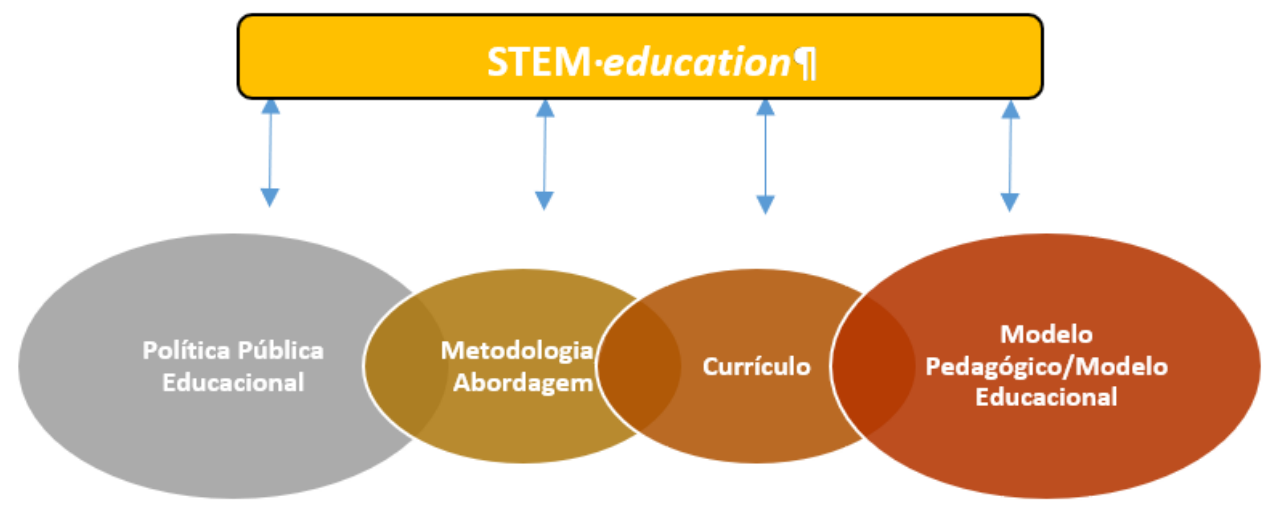

Figura 2: Possíveis interpretações que o movimento STEM education pode assumir.

1. Na primeira possibilidade, STEM education pode visto como uma abordagem ou metodologia (BECKER; PARK, 2011; KELLEY e KNOWLES, 2016; GAMSE et al., 2017). Nesse método, a aprendizagem ocorre a partir da interação com o objeto de estudo, no estilo hands on. Estaria, portanto, mais ligado a uma forma de se ensinar ciências, cujo método é baseado em solução de problemas (Problem Based Learning), desafios, construção de protótipos e nas chamadas metodologias ativas. Enquanto metodologia, não necessariamente tem um protocolo universalmente aceito, mas segue uma direção relativamente estável. Como visto anteriormente, a representação de STEM como metodologia é a que mais tem sido feita no Brasil, possivelmente por encararem as aulas baseadas em projetos e o uso da tecnologia como método de ensino de aprendizagem do STEM. Todavia, essa representação parece ser simplista diante da complexidade política e curricular e tende a ser adotada quando se deseja apresentar STEM como uma receita pronta para melhorar as aulas.

2. Na segunda possibilidade, STEM education pode ser visto como um currículo de ciências incrementado. Nesse caso, a diferença é que o currículo STEM trabalha com competências ao invés de disciplinas, incorpora conteúdos como programação, conceitos da engenharia e do design, em geral, ausentes no ensino básico. Além disso, trata-se de um currículo voltado para a formação profissional e divido em competências, de modo que os saberes produzidos na escola sejam produtivos nas futuras atividades profissionais. Como coloca Lopes (2008), nesse formato de currículo é preconizada a formação educacional “eficiente” da criança em um viés instrumental centralizado na performance dos indivíduos. Dito de outra forma, a perspectiva STEM como um currículo tende a ser mais evidente quando o objetivo é realmente direcionar estudantes para as carreiras STEM e, na maioria dos casos, em detrimento das ciências humanas e sociais.

3. A terceira possibilidade de representação que STEM education pode assumir é a de política pública, a qual visa criar um contingente de professores e profissionais STEM direcionando os alunos para essas áreas. Enquanto uma política, visa interferir diretamente na configuração mercado de trabalho e tem uma clara posição sobre quais rumos deve tomar 
o desenvolvimento do país. Pode estar vinculada ou não à escolha de um modelo educacional específico. Ou seja, tratar-se-ia de uma política pública educacional com influência em vários domínios, articulando o currículo escolar e metodologias de ensino, ou se concentrar em estabelecer investimentos e ações de capacitação de professores STEM. Nos EUA, Reino Unido e Austrália, esse viés de política pública é claramente perceptível, pois são inúmeras as ações vindas do poder público para interferir estruturalmente nos sistemas educacionais (MARGINSON et al, 2013; OBAMA, 2014; RITZ; FAN, 2015; THE WHITE HOUSE, 2016; WONG et al, 2016; REISS; MUJTABA, 2017).

É importante notar que, enquanto política pública, acaba englobando as outras duas representações: atua-se modificando o currículo e a metodologia para atingir determinados fins. No caso específico do movimento STEM education, é possível argumentar que não se trata apenas de uma política pública educacional, mas de uma política educacionaleconômica. Motivados principalmente pelos índices de oferta de trabalho em setores STEM, há um claro senso de que STEM é a casa de máquinas e deve ser privilegiado nas políticas educacionais e receber mais investimento do que as áreas humanas. Diversos governadores, políticos e o ex-presidente dos EUA, Barack Obama, adotaram declaradamente esse posicionamento como norteador das políticas públicas (JASCHIK, 2011; KILEY, 2013; JASCHIK, 2014; THE EDITORS, 2016). Por exemplo, foram criadas aproximadamente 100 escolas secundárias especializadas em STEM em 32 Estados nos EUA de acordo com o NCSSS, um consórcio criado para estimular a criação dessas escolas e propostas STEM (NCSSS, 2017).

Em uma outra face do STEM como política pública, vê-se que diversas organizações se valem do STEM education para promover justiça social através de programas educacionais voltados especificamente para minorias não representadas em áreas STEM, como é o caso do programa MESA (Mathematics, Engineering and Science Achievement) ${ }^{5}$ e do MWM (Million Women Mentors) ${ }^{6}$, entre muitos outros. E nesse caso, tratar-se-ia de uma política pública de inclusão. Tal estratégia foi assumida como política de Estado do governo Barack Obama, o qual financiou diversos programas nesse sentido (THE WHITE HOUSE, 2016). No caso dessas organizações, que têm buscado cada vez mais espaço nos EUA, trabalha-se com a lógica de que mulheres, negros, afro-americanos, asiáticos e latinos não seguem carreiras STEM por falta de acesso, oportunidades, equidade e outras barreiras. Além disso, quando conseguem acesso a essas carreiras, sofrem com a desigualdade salarial e preconceito. As carreiras STEM - mais bem remuneradas e de maior prestígio social, são utilizadas aqui como via de reversão da desigualdade.

Essas organizações, as quais estão profundamente imersas e influenciadas no contexto neoliberal estadunidense, produzem sentidos muito interessantes para o movimento STEM education. Há uma mistura de bases ideológicas progressistas com bases tecnicistas. Ao mesmo tempo em que a emancipação dos oprimidos é realizada, há uma íntima relação com a proteção do mercado de trabalho e da economia do país. Seria interessante se houvesse estudos que se propusessem a compreender como organizações STEM de promoção de justiça social se apropriam das possibilidades de atuação e se relacionam com o sistema ao qual se inserem. 
Por outro lado, ainda do ponto de vista da justiça social, críticos veem que STEM education pode ao mesmo tempo servir para reforçar estigmas e estratificações sociais já existentes, ou seja, acaba por reforçar a desigualdade no acesso às carreiras STEM. Isso porque as medidas tomadas em direção à disseminação de STEM tendem a favorecer apenas essa classe já privilegiada (BASILE; LOPEZ, 2015), enquanto que os programas que tentam reverter tal quadro não são suficientemente apoiados (RINCON et al. , 2014), muitas vezes por serem políticas de governo e não de Estado. Rincon et al., (2014) examinaram 48 programas STEM, cujo público-alvo é a população não representada nessas áreas, e constatou que, apesar da mensagem de equidade ser difundida como lema pelas instituições, os níveis de suporte e investimento dos administradores colocam essa questão em cheque.

Além disso, Wong et al. (2016) mostram que, para muitos educadores, apesar dos argumentos de justiça social serem mais importantes que os argumentos econômicos, o suporte para diversidade presente nos documentos oficiais não foi operacionalizado de fato, nem parece ter havido algum esforço para definir objetivos ou melhorias. Para os autores,

É difícil, para dizer o mínimo, oferecer uma educação eficaz para todos com base nas necessidades de uma indústria que, em última análise, empregará apenas uma pequena proporção de cada parte, embora essa pesquisa sugira que o impacto das organizações envolvidas na rede política STEM esteja em movimento e até mesmo progredindo. (WONG et al, 2016, p. 2362) [Tradução livre]

4. Por fim, na quarta possibilidade de interpretação que temos do movimento STEM education, o temos como um modelo pedagógico de ensino de ciências ou um modelo educacional. Afinal, se é possível reconhecer no movimento STEM education uma clara visão do papel político pedagógico da escola, metodologia, ideologia, proposta de currículo, ciência, etc., distintos dos modelos existentes, tudo indica que estamos tratando de um modelo insurgente, seja ele educacional ou pedagógico ${ }^{7}$. Ou, mesmo que não seja distinto, seria possível reconhecer suas similitudes com os modelos já existentes. Fernandes (2015) analisa e descreve seis modelos pedagógicos de ensino de ciências no Brasil, que seriam: Tradicional, Redescoberta, Tecnicista, Construtivista, Sociocultural e Ciência-TecnologiaSociedade (CTS), e distingue modelos pedagógicos e modelos educacionais da seguinte forma:

Modelos Educacionais são formulações de quadros interpretativos baseados em pressupostos teóricos utilizados para explicar ou exemplificar as ideias educacionais e servem de referência para se refletir sobre o fenômeno educativo em sua totalidade. Modelos Pedagógicos são formulações de quadros interpretativos baseados em pressupostos teóricos utilizados para explicar ou exemplificar as ideias pedagógicas e servem de referência e parâmetro para se entender, reproduzir, controlar e/ou avaliar a prática pedagógica, entendida como uma parte do fenômeno educativo. (FERNANDES, 2015, p. 26-27) 
A autora acrescenta que os modelos pedagógicos sofrem influência dos modelos educacionais, uma vez que este último tem maior amplitude e é mais abstrato, enquanto o segundo é mais localizado e focado na prática pedagógica. Modelo pedagógico de ensino de ciências é entendido aqui, portanto, como um recorte do todo, que seria o modelo educacional.

Nessa perspectiva de modelos, STEM education teria a dimensão de um modelo educacional no qual as lideranças políticas se apropriam e, a partir dele, transformam todo o sistema educacional para além do ensino de ciências; ou, em uma dimensão mais restrita, constitui-se como um modelo pedagógico de ensino de ciências cuja revolução se dá no âmbito do ensino de ciências?

Quando se trata de privilegiar STEM em detrimento das ciências humanas e sociais, ou de assumir que todas as crianças devem ser letradas em STEM para atender às demandas do séc. XXI e que o ensino deve ser profissionalizante, estamos falando de um modelo de educação assumido ${ }^{8}$, e claro, também de uma política pública educacional. Isso ocorre da mesma forma quando se adota a metáfora de pipeline nas ações pró STEM: diplomas de doutorado e carreiras em ciência se transformam nos objetivos da educação (SVINTH, 2006; BANNING; FOLKESTAD, 2012). Por outro lado, quando se trata de uma reforma curricular e metodológica do ensino de ciências, a mudança está, de certa forma, delimitada à dimensão do ensino de ciências como modelo pedagógico. Características como a incorporação da tecnologia e da computação no currículo, o uso de situações-problema baseadas em desafios ambientais e globais e a integração de diferentes áreas, entre outras evidências, levam a crer que STEM education é muito próximo do modelo pedagógico CTS. Já as demandas que o setor econômico imprime no movimento, como a formação profissionalizante, aproximamno do modelo pedagógico tecnicista.

Zeidler nota que

A educação do STEM atualmente defendida falha em não se inserir em um quadro de desenvolvimento ou sociológico coerente que considere explicitamente o crescimento psicológico e epistemológico da criança e ignore o desenvolvimento de caráter ou virtude (...). Falta uma atenção explícita às perspectivas sócio científicas e socioculturais, centrais para formar um senso plenamente desenvolvido de identidade científica que implica necessariamente a promulgação de responsabilidade moral. (ZEIDLER, 2016, p. 16) [Tradução livre]

Para a autora, falta no movimento STEM a preocupação com as questões éticas e sociais da ciência, bem como com a literacidade científica e a construção do conhecimento sobre a natureza da ciência. Não é por coincidência que se nota, como já abordado, um otimismo tecnológico, visão determinista, neutralista e positivista da ciência (FEINSTEIN; KIRCHGASLER, 2015). Para Gough (2014), parece persistir a ideia de que o desenvolvimento futuro e as aplicações da ciência e tecnologia são a salvação de problemas da humanidade. Prevalece uma abordagem instrumentalista: "Esta abordagem da educação STEM é semelhante à abordagem instrumentalista da educação ambiental (...) na qual o papel 
aceito da educação é como uma ferramenta para alcançar objetivos ambientais.” (GOUGH 2014, p. 450) [Tradução livre]. Nesse caso, na tríade Ciência-Tecnologia-Sociedade, o último componente tem um papel figurativo, pois não se reconhece a tecnologia e a ciência como processos sociais complexos. A função trazer elementos do cotidiano do aluno apenas para ilustrar o conteúdo de ciências e tornar as aulas mais interessantes é discutida por Santos (2007) como sendo presente em muitos currículos CTS. Possivelmente, essa função se repete em boa parte das propostas STEM. Da mesma forma, em muitos programas STEM, reforçase a ideia de neutralidade da ciência e a da não-subjetividade das descobertas científicas. Faltam os aspectos socioculturais e sócio científicos centrais para a formação de um senso de identidade científica que necessariamente implica a promulgação da responsabilidade moral, de acordo com Zeidler (2016). Aspectos os quais, diga-se de passagem, são principais no modelo pedagógico sociocultural.

Tal configuração do movimento STEM education coloca em xeque uma possível aproximação com o modelo CTS e conduz à hipótese de que se trata de um novo modelo híbrido, com elementos CTS e tecnicista ao mesmo tempo. CTS em seu argumento, tecnicista em seu contexto de sociedade. Acrescido de uma abordagem que exalta bastante as ideias de maker, design inovador e participação ativa.

Por fim, é importante reiterar que as quatro possibilidades aqui apresentadas não são mutuamente excludentes. Isso quer dizer que entender STEM education como modelo educacional não impede o entendimento do movimento como política educacional. Contudo, essa diferenciação se faz relevante do ponto de vista analítico, pois permite entender os diferentes estágios de desenvolvimento em diferentes contextos nos quais STEM education ganha corpo, como é o caso do Brasil, que mostra uma tendência em direção ao STEM como metodologia em alguns setores isolados, mas aos poucos incorpora elementos bastante característicos do STEM education como modelo educacional em suas recentes reformas curriculares.

\section{Como o movimento STEM education interfere nas políticas de Ensino de Ciências no Brasil?}

Levando em conta a crescente presença do STEM education no Brasil, ou a incorporação das suas bases como uma tendência, a segunda questão a ser colocada trata sobre como o movimento STEM education pode contribuir com o desenvolvimento do ensino de ciências no Brasil. Uma das formas de responder essa questão, é observando o que a controversa experiência em STEM education em outros países tem a nos ensinar. Apesar de responder mais à imposição do mercado do que às demandas sociais, a história do movimento mostra que ele pode ser apropriado e reescrito de inúmeras formas. Isso inclui a utilização do seu potencial reformista para estabelecimento de um ensino de ciências crítico, ético e voltado para a alfabetização científica emancipadora.

Primeiramente, para entender o que ele trouxe de positivo, é preciso considerar algumas críticas válidas contra o movimento STEM education: uma está na visão de ciência 
disseminada, conforme já trabalhado nesse artigo, e é bem sintetizada por Feinstein e Kirchgasler:

O que nos preocupa, em particular, é a possibilidade de que a educação científica promova uma ideia simplificada de sustentabilidade que diminua suas dimensões sociais e éticas, exagerando o papel da tecnologia e a importância do conhecimento técnico à custa de disciplinas não-STEM e conhecimentos não técnicos. (FEINSTEIN; KIRCHGASLER, 2015, p. 123) [Tradução livre]

A outra crítica reside na implementação. Para Breiner (2012), a reforma educacional STEM é mais uma das que falharam por ser pervasiva e sem foco comum. Na implementação, as disciplinas STEM são comumente trabalhadas da forma tradicionalmente individualizada, com pouca integração com outras disciplinas e de forma pouco relevante para os estudantes. Para Gough (2014), os programas muitas vezes não levam em conta que os professores talvez não estejam preparados para tais abordagens, tornando-as ineficazes. Blackley e Howell (2015) colocam que:

Dois motivos fundamentais para a falta de sucesso para a educação STEM como um conceito a ser implementado foram (1) a estrutura curricular, e (2) o nível de habilidade e/ou a reparação dos professores. Essas duas questões estão no cerne de porque as iniciativas STEM falharam, e continuam a falhar, para alcançar as expectativas colocadas sobre elas. (BLACKLEY; HOWELL, 2015, p. 106) [Tradução livre]

Alguns autores trazem à tona as escassas conquistas do movimento STEM em relação à qualidade do ensino, à inclusão de minorias e a uma melhor compreensão da ciência, apesar de todo o potencial transformador prometido no início da reforma. Boa parte dos estudos que partem de perspectivas sociológicas trazem um posicionamento crítico, por vezes avesso, aos resultados que o movimento STEM tem produzido na sociedade, entre eles a manutenção da desigualdade (BLACKLEY; HOWELL, 2015; WONG et al, 2016), racismo (BASILE; LOPEZ, 2015) e desigualdade de gênero (SADLER et al. , 2012; GOUGH, 2014). Blackley e Howell (2015) são contundentes ao afirmar que mesmo após bilhões de dólares investidos em inúmeros programas STEM, os EUA ao longo das últimas décadas, por exemplo, não apresentaram sequer sinais de melhora no ensino de ciências e matemática, avaliados pelo PISA:

Existem resultados significativos nas pontuações PISA, especialmente em áreas que se concentram na aplicação do conhecimento STEM; e há uma aparente incapacidade de professores da escola primária ensinar de forma robusta todos os assuntos do STEM (Marginson et al., 2013). Isso, após 14 anos de promoção e financiamento STEM. Esta é uma estatística notável e desmente porque o STEM persistiu como uma estratégia. (Blackley; Howell, 2015, p. 106). [Tradução livre] 
A grande dificuldade em entendermos STEM education como uma reforma benéfica para o ensino de ciências se dá porque a experiência mostra que algumas iniciativas STEM deixam escapar, seja nas bases ideológicas, seja na implementação em sala de aula, elementos cruciais que diversos educadores vêm defendendo. Esses elementos seriam, por exemplo, a história e filosofia da ciência, debates sobre a natureza da ciência, a natureza transdisciplinar do conhecimento, a integração entre a ciência e as áreas humanas e uma alfabetização científica crítica.

Apesar disso, não podemos ignorar que o movimento tem um apelo interessante na inovação curricular e em metodologias de ensino. Tem também, em muitos casos, impactado positivamente na formação profissional de professores de ciências, além do fato de que programas STEM de inclusão social vêm apresentando resultados invejáveis nas últimas décadas, como é o caso dos programas mencionados anteriormente. As áreas STEM, que historicamente carregam consigo os maiores índices de exclusão de minorias, passaram a ver mudanças positivas nesses índices a partir dessas iniciativas de promoção de justiça social. É justamente nas contradições do movimento que residem as oportunidades de atuação por uma educação científica crítica e com equidade. Não se trata de reconhecer a reforma STEM education como uma inevitabilidade no nosso sistema educacional, visto que é uma tendência global que aos poucos vai sendo incorporada, mas sim de direcionar sua força dominadora.

A partir desse cenário, a questão é refletir sobre qual tipo de reforma STEM education beneficiará nosso sistema educacional. O caminho parece seguir uma associação entre a perspectiva sociocultural e a CTS. Zeidler (2016), por exemplo, defende a integração de STEM em um modelo sociocultural holístico para que não se produza outra geração de cientistas desinteressados, desengajados e desinformados. O desafio diante dos educadores e gestores é conciliar a tendência tecnicista e exclusivamente profissionalizante da educação que cada vez ganha mais força, com os avanços já realizados em direção a uma educação democrática e emancipadora. Outro desafio é não deixar uma percepção positivista e neutralista da ciência dominar os avanços que a sociologia da ciência trouxe nas últimas décadas para o campo do ensino de ciências.

Além disso, é crucial pensar em como envolver os professores de maneira colaborativa e ativa, para que sejam capazes de refletirem e se apropriarem dessa nova proposta incorporando-a em suas próprias práticas e realidades, de modo que faça sentido e atenda às necessidades locais. Via de regra, reformas educacionais sistêmicas tendem a se constituir de maneira vertical, ou seja, parte de uma imposição superior que obriga o corpo docente a adotá-la.

Fato é que não nos beneficiará uma reforma STEM com princípios do modelo CTS, mas que seja praticada como CTs. Da mesma forma, não nos beneficiará o modelo de STEM education voltado para justiça social em que se defenda a inclusão de minorias em STEM apenas porque beneficia a economia do país, mas sim um modelo que se paute em benefícios para as próprias minorias, em como essas minorias podem usufruir do acesso às áreas STEM, algo que é realizado através da alfabetização científica e tecnológica. Um desses inúmeros benefícios, de acordo com Allchin (2014), é estar apto para acessar a confiabilidade das alegações científicas relevantes para a tomada de decisão pessoal e social. 
Ainda, segundo Santos e Mortimer (2002),

É preciso compreender, também, o contexto dos países em que as propostas curriculares de CTS foram desenvolvidas. Por se tratar de países desenvolvidos, a estrutura social, a organização política e o desenvolvimento econômico são bastante diferentes daqueles presentes no contexto brasileiro. Isso implica que seria um contra-senso a transferência acrítica de modelos curriculares desses países para o nosso meio educacional. (SANTOS; MORTIMER, 2002, p. 17)

\section{Considerações finais}

É cedo para falar que STEM irá ocupar parte do vocabulário dos professores brasileiros no dia-a-dia. Porém, como vimos, as diferentes formas pelas quais o movimento com suas bases ideológicas tem se manifestado no Brasil não devem ser ignoradas. STEM education é e ao mesmo tempo faz parte de uma tendência global a qual o Brasil não está imune. Por isso essa tendência precisa ser encarada e pesquisada independentemente da aceitação ou não como modelo a ser seguido.

Aderir ao movimento STEM não é a solução para os problemas no ensino de ciências. Haja visto que países que apresentam continuamente excelentes resultados em ciências e matemática avaliados pelo PISA, não fazem de STEM education uma bandeira. Porém, principalmente em seu caráter inovador e de incorporar a tecnologia e a engenharia no ensino, alguns aspectos do movimento têm muito a contribuir com a educação pública brasileira, que é extremamente anacrônica nos conteúdos e tradicionalista nos princípios pedagógicos.

Por mais que STEM education tenha todos os indícios de uma reforma neoliberal, no seu ponto final, a sala de aula, é possível tirar proveito de sua forma e construir uma educação em ciências mais voltada para o desenvolvimento humano, ético e cognitivo das crianças. É preciso reconhecer o que se tem de positivo nessas propostas STEM em termos de melhoria para o ensino de ciências, para sermos capazes de direcionar o movimento para uma reforma positiva. Principalmente por conta de sua origem neoliberal, a qual pode se traduzir em práticas agressivas de auto disseminação nos sistemas educacionais, é importante sabermos lidar com o seu estabelecimento como modelo a ser seguido. Ademais, é muito importante acompanhar e dimensionar os programas STEM education já em atividade no Brasil e identificar a relação que eles têm com a tendência internacional, sobretudo estadunidense, bem como as políticas públicas que se aproximam da tendência STEM education.

\section{Notas}

1. Essas características podem ser observadas, por exemplo, por meio da consulta de documentos, artigos relacionados e missão institucional dos programas STEM education MESA (Estados Unidos), STEM Brasil (Brasil), Engineering is Elementary (Estados Unidos), STEM Learning (Reino Unido) e The NEED Project (Global). 
2. Wong et al. (2016), por exemplo, notam que a confusão sobre a natureza do STEM education não surpreende, uma vez que o movimento se desenvolve mais a partir de uma racionalidade econômica do que educacional.

3. Por exemplo: (Diniz, 2016; Gomes, 2013, 2015; Lopes, 2017; Santos, 2014).

4. Ver:

https://worldfund.org/site/br/

https://www.positivoteceduc.com.br/blog-robotica-e-stem/o-que-e-stem/ http://steam.colband.net.br/

5. Acessos em 20 abr. 2018.

6. Ver: http://www.washingtonmesa.org/ . Acesso em 20 abr. 2018.

7. Ver: https://www.millionwomenmentors.com/ . Acesso em 20 abr. 2018.

8. Obviamente, uma visão desses componentes também é intrínseca ao Currículo, Metodologia e Política de Ensino, e até mesmo por isso há uma conexão entre as quatro possibilidades de interpretação do movimento STEM education.

9. O trecho de um discurso do ex-presidente Barack Obama ilustra esse modelo: "Nós temos que assegurar que todas as nossas crianças estarão preparadas para os empregos do futuro - o que significa não somente estar apto a trabalhar com computadores, mas desenvolver habilidades analíticas e de programação para suprir nossa economia de inovação. Na nova economia, a ciência da computação não é uma habilidade opcional - é uma habilidade básica (...). ” (The White House, 2016, p. 1) [Tradução livre]

\section{Referências}

AINLEY, M.; AINLEY, J. A Cultural Perspective on the Structure of Student Interest in Science. In: International Journal of Science Education, v. 33, n. 1, p. 51-71, jan. 2011. https://doi.org/10.1080/09500693.2010.518640.

ALLCHIN, D. From Science Studies to Scientific Literacy: A View from the Classroom.

In: Science \& Education, v. 23, n. 9, p. 1911-1932, 2014. https://doi.org/10.1007/s11191-013-9672-8

ANFT, M. The STEM Crisis: Reality or Myth? In: The Chronicle of Higer Education, 2013.

BALL, S. J. Performatividade, privatização e o pós-Estado do bem-estar. Educação \& Sociedade, v. 25, n. 89, pp. 1105-1126, 2004.

BANNING, J.; FOLKESTAD, J. E. STEM Education Related Dissertation Abstracts: A Bounded Qualitative Meta-study. In: Journal of Science Education and Technology, v. 21, n. 6, p. 730-741, 5 dez. 2012. https://doi.org/10.1007/s10956-011-9361-9

BASILE, V.; LOPEZ, E. And Still I See No Changes: Enduring Views of Students of Color in Science and Mathematics Education Policy Reports. In: Science Education, v. 99, n. 3, p. 519-548, 2015. https://doi.org/10.1002/sce.21156.

BECKER, K.; PARK, K. Effects of integrative approaches among science, technology, engineering, and mathematics (STEM) subjects on students' learning: A preliminary meta-analysis. In: Journal of STEM

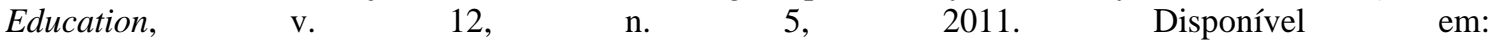
https://jstem.org/index.php/JSTEM/article/download/1509/1394

BELL, D. The reality of STEM education, design and technology teachers' perceptions: a phenomenographic study. In: International Journal of Technology and Design Education, v. 26, p. 61-79, 2016. https://doi.org/10.1007/s10798-015-9300-9 
BLACKLEY, S.; HOWELL, J. A Stem Narrative: 15 Years in the Making. In: Australian Journal of Teacher Education, v. 40, n. 7, 2015. https://doi.org/10.14221/ajte.2015v40n7.8

BRASIL. Ministério da educação. Base Nacional Curricular Comum. Brasília: Ministério da Educação, 2016. Disponível em: < https://goo.gl/rXwo53 >. Acesso em: 26 mai. 2017.

BREINER, J. M. et al. What Is STEM? A Discussion About Conceptions of STEM in Education and Partnerships. School Science and Mathematics, v. 112, n. 1, p. 3-11, jan. 2012.

DINIZ, J. M. et al. What Is STEM? A Discussion About Conceptions of STEM in Education and Partnerships. In: School Science and Mathematics, v. 112, n. 1, p. 3-11, jan. 2012.

BYBEE, R. W. Challenges and Opportunities The Case for Education. EUA: National Science Teachers Association, 2013.

CANNADY, M. A.; GREENWALD, E.; HARRIS, K. N. Problematizing the STEM Pipeline Metaphor: Is the STEM Pipeline Metaphor Serving Our Students and the STEM Workforce? In: Science Education, v. 98, n. 3, p. 443-460, 2014. https://doi.org/10.1002/sce.21108

CARO, D.; LENKEIT, J. Which countries punch above their weight in education rankings? In: The Conversation, p. 1-4, 2015. Disponível em: < https://goo.gl/AxKi6q >. Acesso em: 10 fev. 2017.

CHARETTE, B. R. N. The STEM crisis is a myth. Disponível em: < https://goo.gl/YAh7C4 >. Acesso em: 10 fev. 2017.

CUNNINGHAM, M. From STEM to STEAM: The potential for arts to facilitate innovation, literacy and participatory democracy. Disponível em: < https://goo.gl/85IUIE >. Acesso em: 20 mar. 2017.

DINIZ, A. M. STEM: um novo jeito de ensinar Ciências. In: Estadão, 17 nov. 2016. Disponível em: < https://goo.gl/HPG94t >. Acesso em: 10 out. 2017.

ENGLER, J. STEM education is the key to the US's economic future. In: USNews, 2012. Disponível em: $<$ https://www.usnews.com/opinion/articles/2012/06/15/stem-education-is-the-key-to-the-uss-economicfuture $>$. Acesso em: 20 mar. 2018

ENGLISH, L. D. STEM education K-12: Perspectives on integration. In: International Journal of STEM Education, v. 3, n. 1, p. 3, 2016. https://doi.org/10.1186/s40594-016-0036-1

FEINSTEIN, N. W.; KIRCHGASLER, K. L. Sustainability in Science Education? How the Next Generation Science Standards Approach Sustainability, and Why It Matters. In: Science Education, v. 99, n. 1, p. 121144, 2015. https://doi.org/10.1002/sce.21137

FERNANDES, R. C. A. Inovações pedagógicas no ensino de ciências dos anos iniciais: um estudo a partir de pesquisas acadêmicas brasileiras ( 1972-2012 ). Tese (Doutorado em Educação) - Faculdade de Educação, Universidade Estadual de Campinas, Campinas 2015.

FRIEDMAN, T. L. The world is flat. A brief history of the twenty-first century. Nova York: Farrar, Straus and Giroux, 2005.

GAMSE, B. C.; MARTINEZ, A.; BOZZI, L. Calling STEM experts: how can experts contribute to students' increased STEM engagement? In: International Journal of Science Education, Part B, v. 7, n. 1, p. 31-59, 2017. https://doi.org/10.1080/21548455.2016.1173262

GOMES, P. HP lança site para capacitar professor em Stem. Porvir, Inovações em Educação. Disponível em: $<$ https://goo.gl/NP4fj8 >. 16 abr. 2013. Acesso em: 26 jan. 2017.

GOUGH, A. STEM policy and science education: scientistic curriculum and sociopolitical silences. In: Cultural Studies of Science Education, 2014. https://doi.org/10.1007/s11422-014-9590-3

HOEG, D. G.; BENCZE, J. L. Values Underpinning STEM Education in the USA: An Analysis of the Next Generation Science Standards. In: Science Education, v. 101, n. 2, p. 278-301, 2017. https://doi.org/10.1002/sce.21260 
HONEY, M.; PEARSON, G.; SCHWEINGRUBER, H. STEM Integration in K-12 Education. Washington, D.C.: National Academies Press, 2014. Disponível em: < http://www.nap.edu/catalog/18612 >. Acesso em: 26 mar. 2017.

STEM TASK FORCE REPORT. Innovate A Blueprint for Science, Technology, Engineering, and Mathematics in California Public Education. California department of education. 2014. Disponível em: < https://goo.gl/Bs1KKZ >. Acesso em: 26 mar. 2018.

JASCHIK, S. Florida GOP vs. Social Science. In: Inside Higher Ed, 2011.

. Apology from Obama. In: Inside Higher Ed, 2014.

JOLLY, A. STEM vs. STEAM: Do the arts belong? In: Education Week, p. 2014-2016, 2014.

KELLEY, T. R.; KNOWLES, J. G. A conceptual framework for integrated STEM education. In: International Journal of STEM Education, v. 3, n. 11, 2016. https://doi.org/10.1186/s40594-016-0046-z

KILEY, K. Another Liberal Arts Critic. In: Inside Higher Ed, 2013.

KUENZI, J. J.; MATTHEWS, C. M.; MANGAN, B. F. Science, Technology, Engineering, and and Mathematics (STEM) Education Issues and Legislative Options CRS Report for Congress. Washington DC: [s.n.].

LANGDON, D.; BEEDE, D.; DOMS, M. STEM: Good Jobs Now and for the Future. In: Economics and Statistitcs Administration Issue Brief, v. 3, n. 11, p. 1-10, 2011.

LOPES, A. C.; MACEDO, E. Teorias de currículo. São Paulo: Cortez, 2011.

LOPES, A. C.; Políticas de integração curricular. Rio de Janeiro: Ed. da UERJ, 2008

LOPES, M. Sem esquecer do vestibular, colégio une disciplinas e aposta na prática. Porvir, Inovações em Educação. 4 mai 2017. Disponível em: < https://goo.gl/kMA8vM >. Acesso em: 2 jun. 2017.

MACEDO, Elizabeth. A noção de crise e a legitimação de discursos curriculares. Currículo sem Fronteiras, Pelotas, v. 13, n. 3, p. 436-450, set./dez. 2013. Disponível em $<$ http://www.curriculosemfronteiras.org/vol13iss3articles/emacedo.pdf $>$

MARGINSON, S.; FREEMAN, R.; ROBERTS, K. STEM : country comparisons : international comparisons of science, technology, engineering and mathematics (STEM) education. Australian Council of Learned Academies, 2013.

MAY, G. S.; CHUBIN, D. E. A Retrospective on Undergraduate Engineering Success for Underrepresented Minority Students. In: Journal of Engineering Education, v. 92, n. 1, p. 27-39, 2003. https://doi.org/10.1002/j.2168-9830.2003.tb00735.x

NATIONAL ACADEMIES PRESS. Rising above the Gathering Storm. Washington, D.C.: National Academies Press, 2006. Disponível em: < https://goo.gl/qyGrv2 >. Acesso em: 23 fev. 2017

NCSSS. National Consortium of Secondary STEM Schools. Disponível em: $<$ http://ncsss.org/about $>$. Acesso em: 23 fev. 2017.

OBAMA, B. Preparing Americans with 21 st Century Skills. Washington DC: [s.n.]. Disponível em: < https://goo.gl/q3GWXB >. Acesso em: 15 set. 2017

Organisation for Economic Co-operation and Development. In: PISA 2015 Results in focus: Brasil. OECD. Paris, 2016. Disponível em < https://www.oecd.org/pisa/pisa-2015-results-in-focus.pdf > Acesso em: 17 set. 2017

Organisation for Economic Co-operation and Development. Literacy Skills for the World of Tomorrow: Further Results from PISA 2000. OECD. Paris, 2003. Disponível em: < https://goo.gl/R1sD3B >. Acesso em: 20 set. 2017

RADLOFF, J.; GUZEY, S. Investigating Preservice STEM Teacher Conceptions of STEM Education. In: Journal of Science Education and Technology, 2016. DOI: https://doi.org/10.1007/s10956-016-9633-5 
RADZWILL, N.; BENTON, M.; MOELLERS, C. From STEM to STEAM: Reframing What it Means to Learn. In: STEAM, v. 2, n. 1, p. 1-7, 2015. DOI: https://doi.org/10.5642/steam.20150201.3

REISS, M. J.; MUJTABA, T. Should we embed careers education in STEM lessons? In: The Curriculum Journal, v. 28, n. 1, p. 137-150, 2017. DOI: https://doi.org/10.1080/09585176.2016.1261718

RIGHETTI, S. Austrália Canadá e EUA inspiraram base curricular do Brasil. In: Folha de São Paulo, 2017. 9 de abr. de 2017. Acesso em: 17 set. 2017

RINCON, B. E.; GEORGE-JACKSON, C. E. STEM intervention programs: funding practices and challenges. In: Studies in Higher Education, v. 5079, n. March 2015, p. 1-16, 2014. DOI: https://doi.org/10.1080/03075079.2014.927845

RITZ, J. M.; FAN, S.-C. STEM and technology education: international state-of-the-art. In: International Journal of Technology and Design Education, v. 25, n. 4, p. 429-451, 2015. DOI: https://doi.org/10.1007/s10798-014-9290-z

SADLER, P. M. et al. Stability and volatility of STEM career interest in high school: A gender study. In: Science Education, v. 96, n. 3, p. 411-427, maio 2012. DOI: https://doi.org/10.1002/sce.21007

SANDERS, M. STEM, STEM Education, STEMmania. In: The Technology Teacher, v. 68, n. 4, p. 20-26, 2009.

SANTOS, B. F. DOS. ONG capacita para a educação prática em exatas. In: O Estado de São Paulo, p. 1-2, 2014. 25 de ago. de 2014. Acesso em: 17 set. 2017

SANTOS, W. L. P. D.; MORTIMER, E. F. Uma análise de pressupostos teóricos da abordagem C-T-S (Ciência - Tecnologia - Sociedade) no contexto da educação brasileira. In: ENSAIO - Pesquisa em Educação em Ciências, v. 2, n. 2, p. 1-23, 2002.

SANTOS, W. L. P. DOS. Contextualização no Ensino de Ciências por Meio de Temas Cts em uma Perspectiva Crítica. In: Ciência \& Ensino, v. 1, Número Especial, 2007.

SAXTON, E.; BURNS, R.; HOLVECK, S.; KELLEY, S.; PRINCE, D.; RIGELMAN, N.; SKINNER, E. A. A Common Measurement System for K-12 STEM education: Adopting an educational evaluation methodology that elevates theoretical foundations and systems thinking. In: Studies in Educational Evaluation, v. 40, p. 18-35, 2014. DOI: https://doi.org/10.1016/j.stueduc.2013.11.005

SVINTH, L. “ Leaky pipeline ” - to be or not to be a useful metaphor in understanding why women to a disproportional degree exit from scientific careers. In: Anais do 6th European Gender Research Conference, p. 1-9, 2006.

TAKAHASHI, F. O que os EUA podem ensinar ao Brasil na implantação da Base Curricular. In: Folha de São Paulo, 2017. 07 de mai. de 2017. Acesso em: 17 set. 2017

MCTIC - MINISTÉRIO DA CIÊNCIA, TECNOLOGIA INOVAÇÕES E COMUNICAÇÃO. A ciência e a tecnologia no olhar dos brasileiros. Percepção pública da C\&T no Brasil: 2015. - Brasília, DF: Centro de Gestão e Estudos Estratégicos, 2017.

TEITELBAUM, M. S. The Myth of the Science and Engineering Shortage. In: The Atlantic, p. 8, 2014.19 de mar. de 2014. Acesso em: 17 dez. 2017

THE EDITORS. STEM Education Is Vital--But Not at the Expense of the Humanities - Scientific American. In: Scientific American, out. 2016. Disponível em: <https://www.scientificamerican.com/article/stemeducation-is-vital-but-not-at-the-expense-of-the-humanities/\# > Acesso em: 23 out. 2017.

THE WHITE HOUSE. Fact Sheet: New Progress and Momentum in Support of President Obama's Computer Science for All Initiative. Washington DC, Office of the Press Secretary, 2016. Disponível em: < https://goo.gl/kNUx6l > Acesso em: 23 out. 2017.

THURLEY, C. Infusing the Arts into Science and the Sciences into the Arts: An Argument for Interdisciplinary STEAM in Higher Education Pathways. In: STEAM, v. 2, n. 2, p. 1-8, nov. DOI: https://doi.org/2016. 10.5642/steam.20160202.18 
WONG, V.; DILLON, J.; KING, H. STEM in England: meanings and motivations in the policy arena. In: International Journal of Science Education, v. 38, n. 15, p. 2346-2366, 2016. DOI: https://doi.org/10.1080/09500693.2016.1242818

YI XUE; LARSON, R. C. STEM crisis or STEM surplus? Yes and yes. In: U.S. Bureau of Labor Statistics Monthly Labor Review, v. 5, p. 1-15, 2015.

ZAKARIA, F. Why America's obsession with STEM education is dangerous. In: The Washington Post, p. 6, 26 mar. 2015. Acessado em: https://goo.gl/2MRyr4 Acesso em: 23 out. 2017.

ZEIDLER, D. L. STEM education: A deficit framework for the twenty first century? A sociocultural socioscientific response. In: Cultural Studies of Science Education, v. 11, n. 1, 2016.

\section{Correspondência}

Gustavo Oliveira Pugliese: É doutorando da Faculdade de Educação da Universidade de São Paulo.

E-mail: gustapug@gmail.com

Texto publicado em Currículo sem Fronteiras com autorização do autor 